\title{
POTENCIAL DE FALHA DOS INDIVÍDUOS DE Spathodea campanulata EXISTENTES NO CAMPUS DA UFV, EM VIÇOSA-MG
}

\author{
FAILURE POTENTIAL OF Spathodea campanulata INDIVIDUALS IN THE CAMPUS of \\ UFV IN VIÇOSA, MINAS GERAIS
}

Mariana Campos Abreu Alves ${ }^{1}$, Angeline Martini ${ }^{2}$

\section{RESUMO}

Os benefícios proporcionados pela floresta urbana são inquestionáveis. Contudo, se não for bem planejada e manejada, pode trazer sérios prejuízos. Esta pesquisa teve como objetivo realizar um diagnóstico do potencial de falha dos indivíduos de Spathodea campanulata presentes no campus da UFV na cidade de Viçosa-MG. Para isso, todos os indivíduos da espécie presentes nas composições paisagísticas do campus foram avaliados, no ano de 2018. O método utilizado foi a análise visual, onde se avaliou as características da base da árvore, tronco e copa de cada árvore, atribuindo a cada componente um valor. Esta metodologia permitiu caracterizar o estado dos indivíduos presentes no campus e estabelecer quais os parâmetros exercem maior impacto no risco de queda de cada árvore. No total, foram avaliadas 129 árvores, sendo que destas, 5,4\% foram classificados com alto risco, 62,0\% com risco intermediário e 32,6\% com baixo risco de queda. Dentre todos os parâmetros considerados para a determinação da escala de risco, os que apresentaram maior correlação foram: lesões, cavidades e restrição de espaço na base do tronco (área de canteiro reduzida). Os indivíduos de Spathodea campanulata encontrados no campus da UFV encontram-se em estágio maduro de desenvolvimento, o que contribuiu para intensificar seu potencial de queda. Pode-se concluir que os indivíduos de Spathodea campanulata, por estarem em estágio maduro de desenvolvimento e terem sofrido grande intensidade de podas ao longo de sua existência, precisam de monitoramento para evitar transtornos.

Palavras-chave: floresta urbana; análise de risco; queda de árvores; espatódea.

\section{ABSTRACT}

The benefits provided by urban forest are unquestionable. However, if not properly planned and managed, it can bring serious damage. This research aimed to make a diagnosis of the mechanical failure potential of the specimens of Spathodea campanulata present in the campus of UFV, in the city of Viçosa-MG. For this, all the individuals present in the landscape compositions of the campus were evaluated in 2018 . The chosen method was the visual analysis, in which the characteristics of the tree base, trunk and crown of each tree were evaluated, giving to each component a value. This methodology allowed us to characterize the status of individuals on campus and to establish which parameters have the greatest impact on mechanical failure potential. In total, 129 trees were evaluated, of which $5.4 \%$ were classified as high risk, $62.0 \%$ as intermediate risk and $32.6 \%$ as low risk of fall. The parameters that showed strong correlation to the risk of tree fall were: lesions, cavity and space restriction at the base of the trunk (space for tree). It can be concluded that individuals of Spathodea campanulata, as they are in a mature stage of development and have suffered a great deal of pruning throughout their existence, need monitoring to avoid disorders.

Keywords: urban forest; risk analysis; tree fall; African tulip tree.

Recebido em 20.10.2019 e aceito em 24.01.2020

1 Graduanda em Engenharia Florestal na Universidade Federal de Viçosa. Viçosa/MG. Email: marianaabreualves@gmail.com

2 Engenheira Florestal. Dra ${ }^{\text {. }}$ Professora do Departamento de Engenharia Floresta da Universidade Federal de Viçosa. Viçosa/MG. Email: martini@ufv.br 


\section{INTRODUÇÃO}

A floresta urbana, quando bem gerenciada, proporciona inúmeros benefícios nos aspectos sociais, econômicos e ambientais, que contribuem na melhoria do bem-estar da população (STENICO et al., 2019). Tais benefícios são inquestionáveis, no entanto, a exigência das práticas de manejo excessivas, como podas sucessivas, pode ocasionar prejuízos às árvores, como descaracterização da copa, desequilíbrio estrutural e gerar porta de entrada para ataque de patógenos. Isto ocorre porque muitas espécies são plantadas em locais inadequados ao seu crescimento, necessitando de várias intervenções, como podas, para evitar conflitos com redes elétricas e outros equipamentos urbanos (SANTOS et al., 2015).

Dentre as espécies que compõem a floresta urbana do campus da Universidade Federal de Viçosa (UFV), destaca-se a Spathodea campanulata, que é a sétima espécie arbórea mais plantada no campus (BRIANEZI et al., 2013). Spathodea campanulata, popularmente conhecida como espatódea ou tulipeira, é uma árvore originária da África Tropical, Quênia e Uganda, que pode alcançar $25 \mathrm{~m}$ de altura, apresentando copa densa, no formato globoso (COSTA E LIMA; SILVA JÚNIOR, 2010). Esta planta ornamental é utilizada principalmente pela beleza de suas flores vermelhas com longo período de floração. A beleza de sua floração apreciada pela população e o rápido crescimento da espécie foram os principais motivos para sua implantação em várias cidades brasileiras (COSTA E LIMA; SILVA JÚNIOR, 2010).

Recentemente, segundo a Divisão de Gerenciamento de Resíduos da UFV, responsável pelo manejo da floresta urbana do campus, inúmeros transtornos têm sido relatados pela queda de árvores dessa espécie ou partes delas, sendo, portanto, a principal preocupação referente ao manejo da vegetação no momento.

A queda das árvores pode ser causada por muitos fatores, como período longo de chuvas fortes, podas mal executadas, ventos muito fortes e má formação de raízes (SAMPAIO et al., 2010). Analisar a estabilidade de árvores frente à condições adversas é fundamental nas áreas urbanas, principalmente para diminuir a possibilidade de danos e riscos à integridade das pessoas e patrimônios. Assim, realizar um diagnóstico referente ao risco de queda dos indivíduos dessa espécie torna-se fundamental.

Uma árvore apresenta risco de queda sempre que está estruturalmente debilitada, ou seja, apresenta potencial de falha mecânica e, desde que possa existir um alvo em potencial no momento da queda, que gere prejuízos para a cidade e sociedade (ISA, 2015). A análise visual é um dos métodos amplamente aceitos pelas escolas de arboricultura, com grande aplicação prática (FINK, 2009) e por ser de fácil execução, é o mais utilizado. Nessa análise, realiza-se o diagnóstico visual de toda a parte externa da árvore, da copa à base, levando em consideração todos os problemas verificados, sejam físicos e/ou biológicos (PEREIRA et al., 2011). Esse 
método se destaca por fornecer informações que auxiliam no manejo e gestão da floresta urbana, possibilitando indicar quais intervenções são necessárias, sejam elas tratamentos fitossanitários, podas, ou até mesmo remoção das árvores (SCHALLENBERGER et al., 2010).

É importante destacar que a análise da estrutura da árvore aborda o estudo das propriedades físicas e mecânicas do lenho, que vão desde o sistema radicular e sua interação com o solo e tronco, até a copa e as condições de crescimento (SHORTLE; DUDZIK; SMITH, 2010). Até mesmo para a realização de novas avaliações mais complexas e onerosas, é necessário primeiramente uma análise visual para respaldar a justificativa pelo gasto de tempo e recursos. Torna-se impraticável a utilização de equipamentos para atender toda a demanda dos municípios, devido ao elevado número de vistorias diárias e a demora com a instalação correta das ferramentas usuais. Assim, torna-se fundamental aprimorar tais metodologias.

Neste contexto, o objetivo desta pesquisa foi realizar o diagnóstico do potencial de falha dos indivíduos de Spathodea campanulata presentes no campus da UFV, buscando avaliar a condição atual da floresta urbana e definir quais parâmetros exercem maior influência sobre a probabilidade de queda das árvores.

\section{MATERIAL E MÉTODOS}

A pesquisa foi realizada no campus sede da Universidade Federal de Viçosa, com área de 1.646,55 hectares (ALMEIDA et al., 2016) localizada no município de Viçosa $\left(20^{\circ} 45^{\prime 2} 23^{\prime \prime S}\right.$ e 4252'23”W) na Zona da Mata Mineira. A formação florestal da região é classificada como Floresta Estacional Semidecidual. De acordo com a classificação Köppen, o clima na região é do tipo Cwa, subtropical úmido com chuvas mal distribuídas ao longo do ano, verões quentes e chuvosos e invernos secos e frios (ALMEIDA et al., 2016).

Para realizar a coleta de dados, primeiramente foi preciso quantificar e localizar todos os indivíduos de Spathodea campanulata presentes no campus da UFV. Para isso, utilizou-se como base o estudo desenvolvido por Silva (2019), que identificou todas as árvores que compõem a floresta urbana do campus, excluindo-se remanescentes florestais. Além disso, excursões a campo para conferência e procura de árvores também foram realizadas.

A avaliação de cada árvore foi desenvolvida pela diagnose visual, entre março e agosto de 2018, com base na metodologia descrita por Seitz (2005), que avalia diversos aspectos, copa, tronco e base da árvore, atribuindo valores para o grau de risco de cada parâmetro, bem como alvos e efeitos colaterais.

Segundo a International Society of Arboriculture - ISA (2015), no ato da averiguação é interessante utilizar um processo sistemático, que reúna todas as informações sobre a árvore, sua história e o local onde está inserida. Com isso, pode-se obter uma consistência maior do 
diagnóstico, podendo ser comparada ao longo do tempo com informações coletadas posteriormente, garantindo assim um melhor monitoramento.

Desta forma, um formulário foi previamente definido e elaborado para realizar essa avaliação. O detalhamento das variáveis analisadas foi basicamente o mesmo proposto por Seitz (2005), contudo, algumas adaptações foram realizadas. Destaca-se que a escala de risco para cada atributo, variou de 1 a 5, no entanto atribui-se apenas os valores 1, 3 e 5 e quando não houve risco, o valor foi zero. Alguns dos parâmetros da metodologia original foram descartadas e a definição da escala de cada item foi redefinida para a situação local (Tabela 1).

Tabela 1. Parâmetros analisados na copa, tronco e base das árvores para verificar o potencial de falha dos indivíduos de Spathodea campanulata

Table 1. Parameters analyzed in the crown, trunk and base of trees to verify the failure potential of Spathodea campanulata individuals.

\begin{tabular}{|c|c|c|c|}
\hline \multirow{2}{*}{ Variável } & \multicolumn{3}{|c|}{ Risco } \\
\hline & 1 & 3 & 5 \\
\hline \multicolumn{4}{|l|}{ Copa } \\
\hline \multicolumn{4}{|l|}{ Galho invadindo a via } \\
\hline $\begin{array}{l}\text { Observou-se a presença de galhos no espaço de } 5 \mathrm{~m} \text { acima da } \\
\text { pista de rolamento e, portanto, susceptíveis a choque com veículos } \\
\text { altos }\end{array}$ & $\begin{array}{l}\text { diâmetro do } \\
\text { galho de até } 5 \\
\mathrm{~cm}\end{array}$ & $\begin{array}{l}\text { de } 5 \text { até } 20 \mathrm{~cm} \\
\text { de diâmetro }\end{array}$ & $\begin{array}{c}\text { maior que } 20 \mathrm{~cm} \\
\text { de diâmetro }\end{array}$ \\
\hline \multicolumn{4}{|l|}{ Galhos interferindo na rede } \\
\hline $\begin{array}{l}\text { Observou-se a existência de galhos em contato direto com a rede } \\
\text { ou com possibilidade de interferência. Na UFV só existe a rede de } \\
\text { média tensão, que é de } 13800 \text { volts }\end{array}$ & - & - & $\begin{array}{l}\text { rede de média } \\
\text { tensão }\end{array}$ \\
\hline Galhos secos acima da rede & galhos finos $(<1$ & & $\begin{array}{l}\text { galhos grandes } \\
(>5 \mathrm{~cm} \text { de }\end{array}$ \\
\hline $\begin{array}{l}\text { Observou-se a existência de galhos secos (podres) acima da rede } \\
\text { ou pista }\end{array}$ & $\begin{array}{l}\text { Cm de diâmetro) } \\
\text { ou secos sem } \\
\text { apodrecimento }\end{array}$ & - & $\begin{array}{l}\text { diâmetro) ou com } \\
\text { sinais de } \\
\text { apodrecimento }\end{array}$ \\
\hline Ocos nos galhos & $\begin{array}{l}\text { ocos menores } \\
\text { que } 50 \% \text { da área }\end{array}$ & $\begin{array}{c}\text { ocos de } 50 \% \text { a } \\
70 \% \text { da área }\end{array}$ & $\begin{array}{l}\text { ocos maiores } \\
\text { que } 70 \% \text { da área }\end{array}$ \\
\hline Observou-se a existência galhos com cavidades & $\begin{array}{l}\text { transversal do } \\
\text { galho }\end{array}$ & $\begin{array}{c}\text { transversal do } \\
\text { galho }\end{array}$ & $\begin{array}{l}\text { transversal do } \\
\text { galho }\end{array}$ \\
\hline \multicolumn{4}{|l|}{ Galhos angulados } \\
\hline $\begin{array}{l}\text { Observou-se a existência de galhos que apresentam angulação } \\
\text { principalmente no sentido vertical. Estes galhos têm tendência a } \\
\text { romper longitudinalmente,com posterior quebra }\end{array}$ & $\begin{array}{l}\text { para galhos finos } \\
\text { (menores que } 5 \\
\mathrm{~cm} \text { de diâmetro) }\end{array}$ & $\begin{array}{l}\text { galhos médios } \\
\text { (de } 5 \text { a } 20 \mathrm{~cm} \text { de } \\
\text { diâmetro }\end{array}$ & $\begin{array}{l}\text { galhos grossos } \\
\text { (maiores que } 20 \\
\mathrm{~cm} \text { de diâmetro) }\end{array}$ \\
\hline \multicolumn{4}{|l|}{ Galhos esguios (rabo de leão) } \\
\hline $\begin{array}{l}\text { Observou-se a existência de galhos com folhagem apenas na } \\
\text { extremidade, ocasionados geralmente por podas mal executadas. } \\
\text { Estes galhos são flexíveis, com facilidade de quebra ou } \\
\text { interferência na rede }\end{array}$ & $\begin{array}{l}\text { galhos menores } \\
\text { de } \\
1 \mathrm{~m} \text { de } \\
\text { comprimento }\end{array}$ & $\begin{array}{l}\text { galhos entre } 1 \mathrm{e} \\
3 \mathrm{~m} \text { de } \\
\text { comprimento }\end{array}$ & $\begin{array}{l}\text { galhos maiores } \\
\text { que } 3 \mathrm{~m} \text { de } \\
\text { comprimento }\end{array}$ \\
\hline \multicolumn{4}{|l|}{ Forquilhas ou bifurcações } \\
\hline $\begin{array}{l}\text { As forquilhas são formadas pela inserção de dois ou mais galhos } \\
\text { em ângulo fechado oferecendo alto risco de rompimento. A } \\
\text { presença de vegetação nestas forquilhas nem sempre é um } \\
\text { indicativo de que existem cavidades }\end{array}$ & $\begin{array}{l}\text { forquilhas com } \\
\text { casca inclusa } \\
\text { (angulação entre } \\
\text { galhos menor } \\
\text { que } 25^{\circ} \text { ) }\end{array}$ & $\begin{array}{l}\text { forquilha rachada } \\
\text { com diâmetro } \\
\text { dos galhos entre } \\
5 \text { e } 20 \mathrm{~cm}\end{array}$ & $\begin{array}{l}\text { forquilhas } \\
\text { rachadas com } \\
\text { diâmetro dos } \\
\text { galhos maiores } \\
\text { que } 20 \mathrm{~cm}\end{array}$ \\
\hline Lesões na casca & & lesões de 25 a & lesões maiores \\
\hline $\begin{array}{l}\text { Descascamentos ou queima-de-casca podem indicar galhos } \\
\text { frágeis. Foi analisada a extensão da lesão no perímetro do galho }\end{array}$ & $\begin{array}{l}\text { que } 25 \% \text { do } \\
\text { perímetro }\end{array}$ & $\begin{array}{l}50 \% \text { do } \\
\text { perímetro do } \\
\text { galho }\end{array}$ & $\begin{array}{l}\text { que } 50 \% \text { do } \\
\text { perímetro do } \\
\text { galho }\end{array}$ \\
\hline \multicolumn{4}{|l|}{ Presença de fungos na casca } \\
\hline é sinal claro de deterioração da madeira do interior & fungos & - & - \\
\hline
\end{tabular}




\begin{tabular}{|c|c|c|c|}
\hline \multirow{2}{*}{ Variável } & \multicolumn{3}{|c|}{ Risco } \\
\hline & 1 & 3 & 5 \\
\hline \multicolumn{4}{|l|}{ Copa } \\
\hline$\frac{\text { Insetos perfuradores }}{\text { Observou-se existência de orifícios de insetos na casca dos galhos }}$ & $\begin{array}{l}\text { quando houve } \\
\text { presença de } \\
\text { insetos } \\
\text { perfuradores }\end{array}$ & - & - \\
\hline $\begin{array}{l}\text { Ervas-de-passarinho } \\
\text { A erva-de-passarinho é sintoma claro de árvores estressadas. Sua } \\
\text { presença indica problemas nesta árvore }\end{array}$ & $\begin{array}{l}\text { menos de } 25 \% \\
\quad \text { da copa } \\
\text { apresenta erva- } \\
\text { de-passarinho }\end{array}$ & $\begin{array}{l}\text { de } 25 \text { a } 50 \% \text { da } \\
\text { copa está com } \\
\text { erva-de- } \\
\text { passarinho }\end{array}$ & $\begin{array}{l}\text { mais de } 50 \% \text { da } \\
\text { copa está com } \\
\text { erva-de- } \\
\text { passarinho }\end{array}$ \\
\hline $\begin{array}{l}\text { Folhagem rala } \\
\text { Durante o período vegetativo de cada espécie as colorações das } \\
\text { folhas podem variar. Quando sofrem estresse, as árvores tendem } \\
\text { a produzir menos folhas, de tamanho menor e às vezes de } \\
\text { coloração mais clara. Pode ser um indicativo de problemas no } \\
\text { enraizamento ou outros distúrbios que estão afetando a fisiologia } \\
\text { da árvore }\end{array}$ & $\begin{array}{l}\text { menos de } 25 \% \\
\text { da copa está } \\
\text { afetada } \\
\text { (mudança de } \\
\text { coloração ou } \\
\text { densidade de } \\
\text { folhagem) }\end{array}$ & $\begin{array}{l}\text { de } 25 \text { a } 50 \% \text { da } \\
\text { copa está } \\
\text { afetada }\end{array}$ & $\begin{array}{l}\text { mais de } 50 \% \text { da } \\
\text { copa está } \\
\text { afetada }\end{array}$ \\
\hline $\begin{array}{l}\text { Marca de poda } \\
\text { Observou-se marcas de podas anteriores na copa, que deixaram } \\
\text { inserções de galhos defeituosos e fragilizados }\end{array}$ & $\begin{array}{l}\text { galhos cortados } \\
\text { menores que } 5 \\
\mathrm{~cm} \text { de diâmetro }\end{array}$ & $\begin{array}{l}\text { galhos cortados } \\
\text { de } 5 \text { a } 20 \mathrm{~cm} \text { de } \\
\text { diâmetro }\end{array}$ & $\begin{array}{l}\text { galhos cortados } \\
\text { com mais de } 20 \\
\text { cm de diâmetro }\end{array}$ \\
\hline $\begin{array}{l}\text { Poda unilateral } \\
\text { A poda de apenas um lado da copa pode ajudar a provocar a } \\
\text { queda das árvores }\end{array}$ & $\begin{array}{l}\text { menos de } 25 \% \\
\text { da copa retirada } \\
\text { unilateralmente }\end{array}$ & $\begin{array}{l}\text { de } 25 \text { a } 50 \% \text { da } \\
\text { copa retirada } \\
\text { unilateralmente }\end{array}$ & $\begin{array}{l}\text { para mais de } \\
50 \% \text { da copa } \\
\text { retirada } \\
\text { unilateralmente }\end{array}$ \\
\hline \multicolumn{4}{|l|}{ Tronco } \\
\hline $\begin{array}{l}\text { Invasão da pista ou calçada } \\
\text { Troncos inclinados invadindo a via de rolamento }\end{array}$ & $\begin{array}{l}\text { troncos }<10 \mathrm{~cm} \\
\text { de diâmetro }\end{array}$ & $\begin{array}{c}\text { troncos de } 10 \mathrm{a} \\
40 \mathrm{~cm}\end{array}$ & $\begin{array}{l}\text { maiores que } 40 \\
\mathrm{~cm}\end{array}$ \\
\hline \multicolumn{4}{|l|}{ Danos de batidas e lesões de casca } \\
\hline $\begin{array}{l}\text { Observar danos na casca ocorridos por batidas, pois dependendo } \\
\text { da extensão do tronco afetado, pode levar a deficiência do sistema } \\
\text { radicular, provocando a queda posteriormente }\end{array}$ & $\begin{array}{l}\text { menos de } 25 \% \\
\text { do perímetro do } \\
\text { tronco }\end{array}$ & $\begin{array}{l}\text { para } 25 \text { a } 50 \% \\
\text { do perímetro do } \\
\text { tronco }\end{array}$ & $\begin{array}{l}\text { mais de } 50 \% \text { do } \\
\text { perímetro do } \\
\text { tronco }\end{array}$ \\
\hline$\frac{\text { Cavidades }}{\text { Observou-se a existência de cavidades }}$ & $\begin{array}{l}\text { para ocos com } \\
\text { menos de } 50 \% \\
\text { da área } \\
\text { transversal do } \\
\text { tronco }\end{array}$ & $\begin{array}{l}\text { de } 50 \text { a } 70 \% \text { da } \\
\text { área transversal } \\
\text { do tronco está } \\
\text { oca }\end{array}$ & $\begin{array}{l}\text { mais de } 70 \% \text { da } \\
\text { área transversal } \\
\text { do tronco está } \\
\text { oca }\end{array}$ \\
\hline$\frac{\text { Obturações, corpos estranhos no interior do tronco }}{\text { A presença de materiais para tapar um oco ou danificar a madeira }}$ & $\begin{array}{l}\text { presença de } \\
\text { corpos estranhos } \\
\text { (pregos, arames, } \\
\text { fios, concreto) }\end{array}$ & $\begin{array}{l}\text { para obturações } \\
\text { até } 25 \% \text { do } \\
\text { perímetro do } \\
\text { tronco }\end{array}$ & $\begin{array}{l}\text { obturações } \\
\text { maiores que } 25 \% \\
\text { do perímetro do } \\
\text { tronco }\end{array}$ \\
\hline
\end{tabular}

\section{Forma do tronco}

Troncos acanelados em espécies que normalmente não possuem esta característica são devidos ao crescimento localizado das células, o que pode indicar distúrbios no câmbio, consequentemente riscos

\section{Orifícios de insetos}

A existência de insetos no tronco pode ser observada pelos orifícios de eclosão, de respiração e eliminação de resíduos, pela "serragem" acumulada na base da árvore ou exsudação de gomas ou resinas. A presença de insetos indica problemas com estas árvores, embora nem sempre isto signifique um risco elevado de queda. Os cupins presentes nas árvores indicam cavidades e madeira em decomposição, normalmente consequência de lesões antigas

\section{Fungos}

Assim como os insetos a presença de corpos frutíferos de fungos é um sinal evidente de deterioração da madeira dentro do tronco

se houver acanelamento. 


\begin{tabular}{llccc} 
& & & Risco \\
Variável & & 1 & 3 & 5 \\
\hline & Base & & \\
\end{tabular}

\section{Brotação adventícia}

Quando uma árvore apresenta muitos brotos na base do tronco, há normalmente uma deficiência na circulação da seiva, que deveria alimentar as raízes finas, indicando problemas nas raízes desta árvore. Essa brotação normalmente não oferece risco e haverá apenas um grau de risco mínimo para este item de avaliação

\section{Lesões na base do tronco}

Qualquer lesão na base do tronco deve ser avaliada com cuidado, pois é esta parte da árvore que sofre as maiores tensões e pressões

\section{Cavidades}

Presença de ocos na estrutura das raízes até o solo

\section{Presenca de ninhos e colmeias de insetos}

A presença de insetos na base da árvore também é sinal de debilidade, embora a maioria destes seja apenas oportunista. Eles aproveitam um espaço disponível, gerado a partir de problemas anteriores

\section{Fungos}

Presença de fungos

\section{Raízes adventícias}

As raízes de cada espécie arbórea têm uma estrutura especifica, e normalmente não são encontradas raízes finas saindo da base do tronco ou de raízes de diâmetros grandes. Quando isto ocorre é sinal de problemas nas raízes de sustentação da árvore

\section{Elevação e fissura do solo}

Ás vezes a queda de árvores é precedida de deformações do solo próximo à base da árvore. Uma pequena elevação ou rachaduras no solo ou piso pode indicar a falência das raízes. Não confundir com a elevação do solo como consequência do crescimento em diâmetro das raízes em solos muito compactados ou mal drenados

\section{Espaco ou área Livre}

foi analisado se a árvore tinha espaço adequado para desenvolver suas raízes e estruturas de sustentação. Espaços pequenos podem aumentar o risco de queda. Área do canteiro maior que $2 \mathrm{~m}^{2}$ foi considerada como de risco zero

\section{Neilóide}

A maioria das árvores apresenta uma estrutura geométrica desenvolvida na base do tronco que auxilia para a melhor sustentação da planta, denominada neilóide. Quando esta forma não é identificada, os troncos são cilíndricos até o contato com o solo, havendo indícios de aterros. Estes aterros podem danificar as raízes, levando à instabilidade da árvore, ou ocultar problemas na base do tronco original

\section{Raízes cortadas}

Poda de raízes é um dos fatores que mais influenciam na queda de árvores. Toda árvore que teve suas raízes podadas seja para se ajustar a canteiros em calçadas ou devido a escavações para a passagem de tubulações subterrâneas é considerada de risco. A poda de raiz foi constatada visualmente devido as marcas deixadas com a mudança do nível do solo, bem como perda de solo
Presença de brotações

adventícias

$\begin{array}{ccc}\begin{array}{c}\text { lesões menores } \\ \text { que } 10 \% \text { do } \\ \text { perímetro }\end{array} & \begin{array}{c}\text { lesões de } 10 \text { a } \\ 50 \% \text { do } \\ \text { perímetro }\end{array} & \begin{array}{c}\text { lesões maiores } \\ \text { que } 50 \% \text { do } \\ \text { perímetro }\end{array} \\ \begin{array}{c}\text { ocos menores } \\ \text { que } 50 \% \text { da área } 50 \text { a } 75 \% \text { da } \\ \text { transversal do } \\ \text { tronco }\end{array} & \begin{array}{c}\text { área transversal } \\ \text { do tronco está } \\ \text { oca }\end{array} & \begin{array}{c}\text { mais de } 75 \% \text { da } \\ \text { área transversal } \\ \text { está oca }\end{array} \\ & & \text { conal }\end{array}$

Presença de ninhos e

colmeias de insetos presença de corpos frutíferos

Presença de Raízes adventícias presença de elevação do solo

área do canteiro de $1 \mathrm{~m}^{2}$ a $2 \mathrm{~m}^{2}$

área do canteiro igual a $1 \mathrm{~m}^{2}$ ou menor

sem área de canteiro/ área toda

mpermeabilizad a
menos de $50 \%$ de raízes cortadas
mais de $50 \%$ de 100\% de raízes cortadas em volta do tronco


Vale destacar ainda, que em análise de risco de queda de árvores, há uma rotina básica de boas práticas que consiste em primeiramente avaliar a relevância dos alvos na zona de impacto no caso de colapso de galhos ou mesmo de queda da árvore (CARVALHO; FERREIRA, SANTOS, 2019). Esta ação não foi adotada na presente pesquisa, devido a semelhança entre as áreas, todas classificadas como de intenso fluxo de pessoas, sendo assim, realizou-se exclusivamente a probabilidade de falha mecânica das árvores.

Ao final da aplicação do formulário proposto por Seitz (2005), cada indivíduo recebeu um valor final para a copa, para o tronco e para a base do tronco. A esses valores foi aplicado peso 1 para o total da copa, peso 3 para o total do tronco e peso 5 para o total da base da árvore, pois entende-se que a copa oferece menor risco e a base do tronco maior risco. Este procedimento de média ponderada foi necessário para aumentar a discrepância entre os resultados, atribuindo maior importância aos indivíduos com a base do tronco debilitada.

As árvores foram agrupadas em três classes: 1 (maior risco) - indivíduos com valores maiores ou iguais a 80; 2 (risco intermediário) - valores entre 79 e 40; 3 (menor risco) - valores menores que 40. Para cada classe foram recomendadas medidas de intervenção para melhorar as condições das árvores.

Os valores atribuídos a cada parâmetro analisado foram somados para cada parte da árvore separadamente, assim cada indivíduo obteve um somatório para a copa, um para tronco e outro para a base da árvore. A esses valores do somatório de cada parte da árvore aplicou-se a correlação simples entre os parâmetros analisados da respectiva parte (copa, tronco e base da árvore) com o seu referente somatório total. Assim, cada parâmetro foi pareado individualmente e teve sua análise de importância dentro da sua classe representativa, permitindo estabelecer quais parâmetros exerceram muito impacto no potencial de falha espécie.

A correlação foi calculada através da utilização da função "CORREL" do Excel. A análise de correlação resulta no grau de relacionamento entre duas variáveis, sendo que quando o resultado for positivo, demonstra uma correlação direta e quando negativo, inversa. O coeficiente foi classificado conforme seu valor, em: nulo - para correlação igual a 0 ; fraco - de 0 até 0,30 ; médio - entre 0,30 e 0,60; forte - de 0,60 até 0,90; fortíssimo- de 0,90 até menos que 1 e perfeito - para correlação igual a 1 (GONZÁLEZ, 2000).

\section{RESULTADOS E DISCUSSÃO}

\section{Caracterização dos indivíduos de Spathodea campanulata}

Ao todo, foram encontrados no campus 129 exemplares da espécie, com altura média de 15,6 m e máxima de 32,9 m, com DAP médio de 53,3 cm (SILVA, 2019). Pesquisas anteriores 
revelaram que a idade média aproximada dos indivíduos de Spathodea campanulata presente no campus é de cinquenta anos (SILVA, 2019).

A maioria dos indivíduos de espatódea encontram-se em locais com frequência alta ou média de trânsito de pessoas e veículos (CARMO, 2007), nos quais já ocorreram queda de árvores total ou de parte desta espécie dentro do campus.

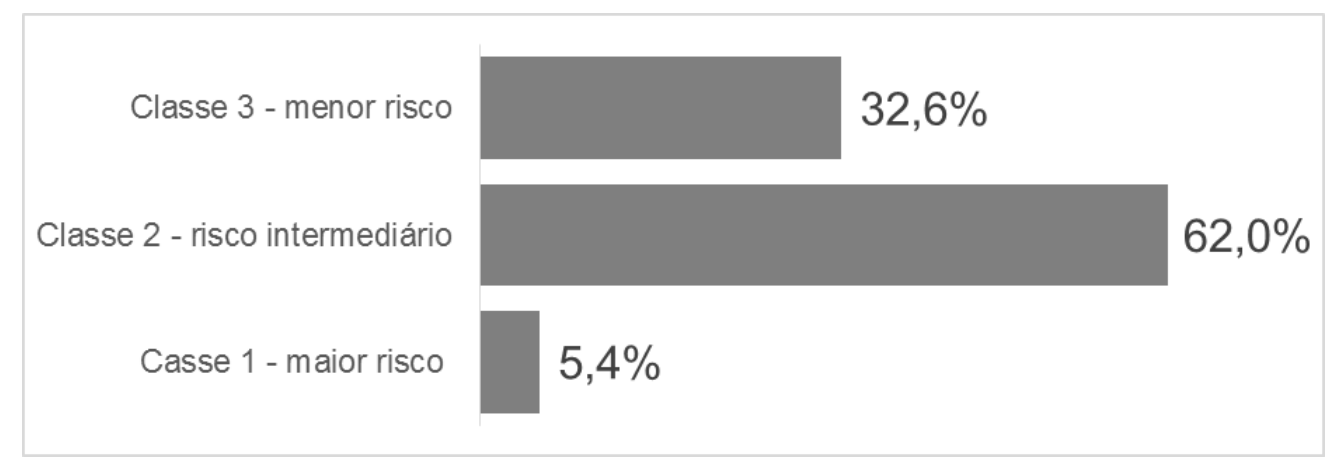

Figura 1. Distribuição dos indivíduos de Spathodea campanulata existentes no campus sede da UFV em suas respectivas classes de risco

Figure1. Distribution of Spathodea campanulata specimens on UFV campus in their respective risk classes

Apenas sete indivíduos foram classificados como de maior risco. Todos esses indivíduos sofreram poda de copa e de raízes. Além disso, compõe essa classe, 4 indivíduos com cavidade no tronco, comprometendo sua secção em mais de 50\%. Para as árvores dessa primeira classe, onde estão presentes os indivíduos que possuem valores de risco mais altos na avaliação do tronco e da base, indica-se a remoção.

$\mathrm{Na}$ classe intermediária de risco, encontram-se oitenta árvores amostradas, com maior risco na avaliação da copa, não oferecendo tanto risco estrutural (tronco e base da árvore) comparado à classe das árvores de alto risco. As práticas de manejo recomendadas são as podas de limpeza e de adequação, para aquelas que estão em contato direto com a fiação elétrica e para as que apresentem galhos a uma altura baixa (menor que $2,1 \mathrm{~m}$ ), prejudicando a passagem de pedestres pela calçada.

$\mathrm{Na}$ classe com menor grau de risco, encontram-se quarenta e dois indivíduos. Essas árvores também possuem maior risco na copa, que podem ser solucionadas com podas corretas, bem como como monitoramento, a fim de manter harmonia das espatódeas com o meio ao qual estão inseridas.

Algumas características gerais observadas nos indivíduos de espatódea merecem destaque. Cerca de $70,5 \%$ das árvores sofreram poda de raízes. Esse tipo de poda é uma das piores práticas além da poda severa da copa, pois podem potencializar o ataque de insetos e doenças, aumentando o risco de queda das árvores (PEREIRA, 2017). 
Foram encontrados orifícios de insetos nos galhos de 14,7\% dos indivíduos e também no tronco de $16,2 \%$, sendo estes últimos geralmente verificados na presença de lesão de casca aparente ou em restos de podas que não foram realizadas devidamente, abrindo portas para a entrada e estabelecimento dos mesmos. Já na base das árvores foi detectada a presença de formigueiros em $31,8 \%$ dos indivíduos.

Outro fator que influenciou no potencial de falha foi a presença de cavidades, sendo que ao todo 6 indivíduos apresentaram cavidades. Nessas condições as árvores ficam susceptíveis a biodeterioração do lenho por microrganismos xilófagos, cupins e brocas da madeira, podendo ocasionar, na maioria das vezes, a sua queda ou morte (COSTA-LEONARDO, 2002). Esta caraterística contribuiu significativamente para a categorização dos indivíduos na classe de maior risco (Figura 2).
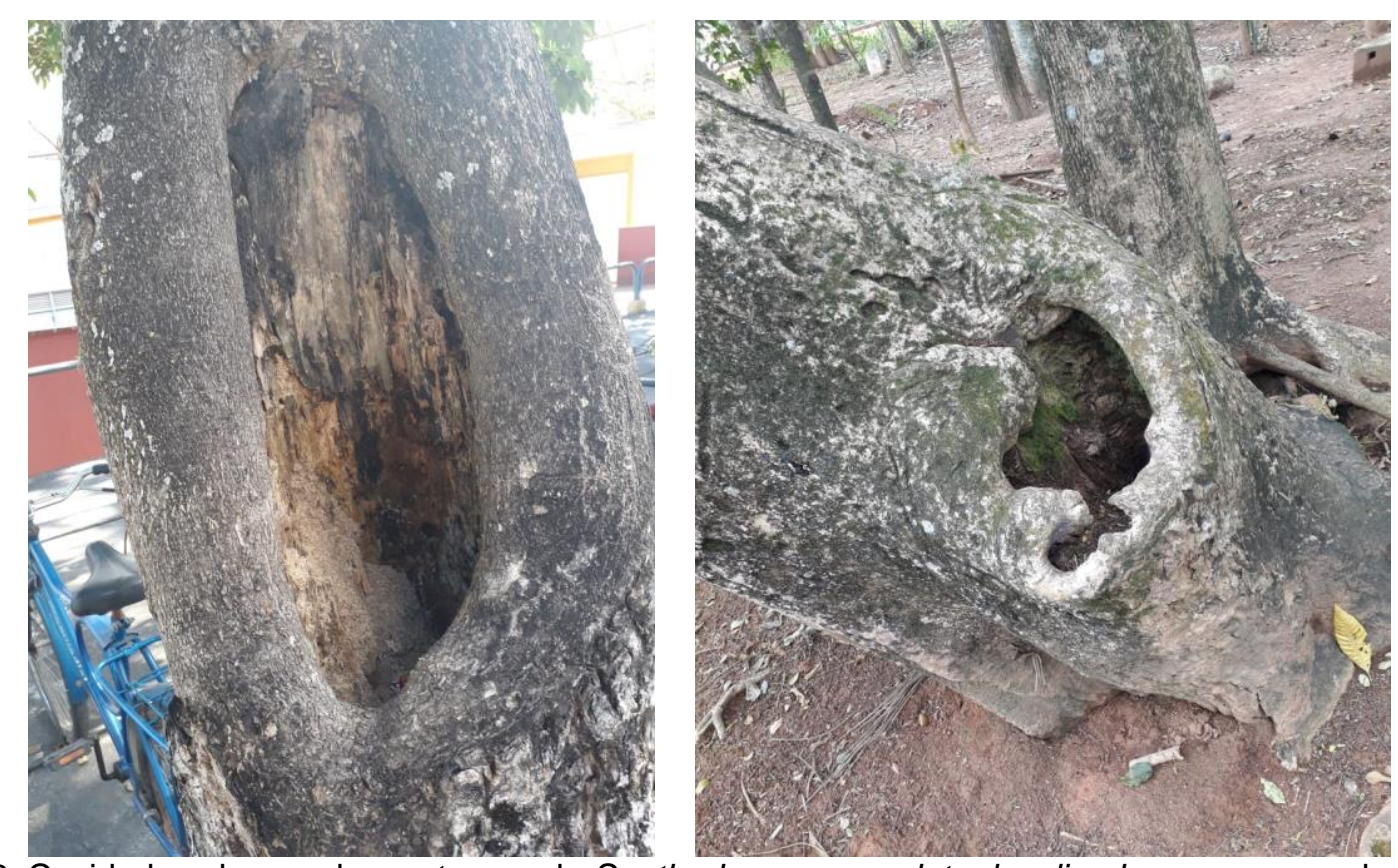

Figura 2. Cavidades observadas no tronco de Spathodea campanulata localizadas no campus da UFV Figure 2. Cavities observed in the trunk of Spathodea campanulata located on the UFV campus

Embora 4,6\% das árvores estivessem ocas é importante destacar que o processo de senescência dos tecidos, ao evoluir sobre uma lesão, pode chegar ao extremo de transformar partes da árvore em uma estrutura oca, mas que ainda assim é estável (CARVALHO; FERREIRA, SANTOS, 2019). A importância de se estudar as vantagens e desvantagens biofísicas de existir partes ocas é fundamental para a compreensão da ecologia das plantas e suas interações com o meio, contudo, no ambiente urbano admite-se que a existência de ocos está em geral vinculada ao aumento do risco à vida e ao patrimônio (SPATZ; NIKLAS, 2013).

Cerca de $12 \%$ dos indivíduos avaliados não possuem espaço adequado para o crescimento das árvores, valor baixo quando comparado ao encontrado por Bezerra (2017) em uma Avenida de Baraúna - RN, em que 35,93\% dos indivíduos possuíam área restrita de 
crescimento. Essa condição, segundo os autores, impede a infiltração de água no solo ou até mesmo o seu encharcamento, em caso de solo compactado, podendo assim, favorecer o crescimento de raízes superficiais e levantamento de calçadas.

O campus universitário é uma área de grande fluxo de pedestres e veículos e, portanto, sofre intervenções referentes a obras civis continuadamente, e uma ação que influencia diretamente na floresta urbana são as reformas de calçadas, que por vezes passam a ocupar o espaço anteriormente composto por raízes. Cerca de $22,5 \%$ dos indivíduos estão com a base da árvore aterrada, sem visualização de neilóide, resultado da instalação de novas calçadas após a presença da planta já estabelecida. Seitz (2005) afirma que, por estarem aterradas, as árvores podem ter suas raízes danificadas, ocasionando assim problemas estruturais.

Independente da análise de risco, a caracterização dos indivíduos de Spathodea campanulata presentes no campus revelaram o estágio senescente e comprometedor de sua estrutura física, fragilizada pela prática inadequada de manejo. A senescência pode ser observada quando as árvores mostram sinais evidentes e visíveis de redução biológica do crescimento, como resultado da diminuição das atividades fisiológicas (IMAÑA; SILVA; PINTO, 2005). Esse processo de senescência foi constatado em $83 \%$ da população amostrada por esse estudo, caracterizados pela folhagem rala e pela presença de galhos secos ou mortos.

\section{Parâmetros que exercem maior impacto na análise de risco}

Qualquer injúria que possa afetar o tronco, sistema radicular, galhos ou copa pode intensificar situações de risco por tornar a estrutura do indivíduo mais frágil, além de ser forte indício de risco de queda. Outras características importantes são os problemas fitossanitários, causados por agentes biológicos que usam a árvore como hospedeiro intermediário ou parasita, influenciando na vitalidade e estabilidade estrutural desta (BOBROWSKI; VASHCHENKO; BIONDI, 2010). Portanto é importante avaliar diferentes variáveis para gerar informações que darão respaldo para os resultados da avaliação.

A análise dos parâmetros que exercem maior impacto na análise de risco, obtida por meio de correlação simples entre as variáveis e seus respectivos valores, demostram os itens que necessitam de maior cuidado e atenção, inclusive para o manejo da floresta urbana (Tabela 1). 
Tabela 1. Correlação dos parâmetros avaliados em Spathodea campanulata com o valor final da copa, do tronco e da base da árvore

Table 1. Correlation of the parameters evaluated in Spathodea campanulata with the final note of the crown, trunk and base

\begin{tabular}{|c|c|c|}
\hline PARÂMETROS AVALIADOS & $\begin{array}{c}\text { VALOR DE } \\
\text { CORRELAÇÃO }\end{array}$ & $\begin{array}{l}\text { CLASSIFICAÇÃO DA } \\
\text { CORRELAÇÃO }\end{array}$ \\
\hline \multicolumn{3}{|c|}{ COPA DA ÁRVORE } \\
\hline Invasão de galhos acima da via ou pista & 0,226 & FRACA \\
\hline Galhos ou folhas grandes interferindo na rede/ pista & $-0,044$ & FRACA* \\
\hline Galhos secos acima da rede & 0,607 & FORTE \\
\hline Ocos nos galhos & 0,451 & MÉDIA \\
\hline Galhos angulados & 0,405 & MÉDIA \\
\hline Galhos esguios (rabo de leão) & 0,312 & MÉDIA \\
\hline Forquilhas ou bifurcações & 0,226 & FRACA \\
\hline Lesões de casca nos galhos & 0,424 & MÉDIA \\
\hline Fungos & $-0,044$ & FRACA* $^{*}$ \\
\hline Insetos perfuradores & 0,507 & MÉDIA \\
\hline Ervas-de-passarinho & 0,068 & FRACA \\
\hline Folhagem rala & 0,491 & MÉDIA \\
\hline Poda & 0,505 & MÉDIA \\
\hline Poda unilateral & 0,274 & FRACA \\
\hline \multicolumn{3}{|c|}{ TRONCO DA ÁRVORE } \\
\hline Invasão da pista ou calçada & $-0,014$ & FRACA* $^{*}$ \\
\hline Inclinação & 0,323 & MÉDIA \\
\hline Danos de batidas e lesões de casca & 0,697 & FORTE \\
\hline Cavidades & 0,756 & FORTE \\
\hline Obturações, corpos estranhos no interior do troncc & 0,199 & FRACA \\
\hline Forma do tronco & 0,000 & NULA \\
\hline Orifícios de insetos & 0,655 & FORTE \\
\hline Fungos & 0,572 & MÉDIA \\
\hline \multicolumn{3}{|c|}{ BASE DA ÁRVORE } \\
\hline Brotação adventícia & 0,106 & FRACA \\
\hline Lesões na base do tronco & 0,350 & MÉDIA \\
\hline Cavidades na base do tronco & 0,422 & MÉDIA \\
\hline Presença de ninhos e colmeias de insetos & 0,200 & FRACA \\
\hline Fungos & 0,063 & FRACA \\
\hline Raízes adventícias & 0,000 & NULA \\
\hline Elevação e fissura do solo & $-0,015$ & FRACA* \\
\hline Canteiro, espaço ou área livre & 0,675 & FORTE \\
\hline Neilóide & 0,093 & FRACA \\
\hline Poda de raízes & 0,584 & MÉDIA \\
\hline
\end{tabular}

${ }^{*}$ Correlação negativa: Um coeficiente de correlação negativa significa que, para qualquer duas variáveis $X$ e $Y$, um aumento em $X$ está associado a uma diminuição em $Y$

Dos 14 parâmetros avaliados na copa, 50\% tiveram correlação média, ou seja, têm influência significativa no valor final da condição da parte aérea. Dentre estes parâmetros temse a poda, que foi realizada de forma incorreta nestes indivíduos ao longo de sua existência, tendo como consequência a compartimentalização incompleta, visivelmente observada. Esta 
situação pode servir como porta de entrada para fatores bióticos e abióticos deteriorarem a região afetada, além disso, a má execução de podas pode levar ao surgimento de ocos nos galhos (SEITZ, 2005), parâmetro também observado com o mesmo grau de correlação.

A espécie tem tendência à queda de galhos (BISPO, 2017). Este fator pode ser confirmado pelo único parâmetro que obteve correlação forte, referente aos galhos secos acima da rede ou pista. Portanto é de suma importância o monitoramento para realização de eventuais podas de limpeza visando evitar acidentes.

$\mathrm{Na}$ parte do tronco as variáveis que apresentaram maior correlação com o risco de queda foram os danos de batidas e lesões de casca e os orifícios de insetos e cavidades. Estes foram os que mais danificaram a parte estrutural da árvore, diminuindo sua resistência física e deixando-as propensas a sofrerem quedas mais facilmente. Segundo Seitz (2005), a área da cavidade tem influência sobre o risco de queda da árvore, sendo que quanto maior for a extensão do buraco maior o risco de queda futura, portanto deve ser monitorada a fim de evitar danos aos possíveis alvos.

Já a inclinação apresentou correlação média, visto que todos os indivíduos possuíam uma leve inclinação (menor que $3^{\circ}$ ). Somente dois indivíduos receberam maiores valores por apresentarem inclinação superior a $40^{\circ}$, sendo explicado pelo fato de estarem em terreno declivoso. Os fungos no tronco também tiveram uma correlação média, porém, em apenas duas árvores foi possível observar a presença de corpo frutífero. Embora tenha apresentado baixa ocorrência, este é um parâmetro que influência na categorização do risco por ser extremamente deletério para planta, uma vez que sua presença indica podridão demonstrando que o indivíduo está bastante frágil.

$\mathrm{Na}$ base da árvore, os parâmetros que apresentaram correlação média foram as lesões, cavidades e podas de raízes. Esses parâmetros estão interligados, pois as podas podem provocar aberturas ou ferimentos que posteriormente podem virar cavidades devido a atividade dos insetos e das condições climáticas. Manter a base da árvore saudável é de extrema importância para o seu estabelecimento, sendo necessário um manejo adequado dessa região.

A condução de nutrientes e sustentação pode ser diretamente afetada por influência da deterioração da base da árvore, reduzindo o vigor do indivíduo como um todo, observando-se, por exemplo, a queda de folhas fora da época correta, sendo um indicativo de problemas fisiológicos (MILANO; DALCIN, 2000).

A variável que apresentou maior correlação como o potencial de falha das árvores foi a área livre de canteiro, onde $18 \%$ das árvores estão em locais sem restrição para o crescimento, cerca de $69 \%$ se encontram em locais com área maior que $1 \mathrm{~m}^{2}$ e outras $12 \%$ apresentam restrição total de espaço para o crescimento das raízes, com evidências notórias de levantamento de calçada, indicando a presença de barreiras físicas ou compactação do solo. A 
área livre do canteiro é essencial por garantir a percolação de água, atividade microbiológica e troca de nutrientes, favorecendo o desenvolvimento do sistema radicular das árvores.

A situação da UFV não difere da realidade brasileira quanto ao problema com dimensões das calçadas. Apesar do espaço para o fluxo de pedestres ser bem amplo, há limitações quanto às dimensões dos canteiros destinados aos componentes arbóreos. Segundo Pereira (2006), a limitação de espaço nas calçadas das vias públicas se deve ao fato de que elas não foram projetadas para receber a floresta urbana, uma vez que o traçado urbano opta pelo incremento de áreas para veículos, em detrimento do bem-estar e do conforto dos pedestres.

\section{CONCLUSÕES}

Os indivíduos de Spathodea campanulata encontrados no campus da Universidade Federal de Viçosa encontram-se em estágio maduro de desenvolvimento, o que contribuiu para intensificar seu potencial de queda. Este estágio de desenvolvimento pode ter sido influenciado pelas técnicas de manejo aplicadas, principalmente por terem sofrido grande intensidade de podas ao longo da vida.

De todos os parâmetros avaliados, os que apresentaram maior correlação com o potencial de falha mecânica das árvores foram também os que mais causam danos estruturais, sendo eles, lesões, cavidades e restrição de espaço na base do tronco. Em relação à copa, a presença de galhos secos sobre a rede elétrica também teve forte correlação e por isso recomenda-se o monitoramento para possíveis podas de limpeza. Para o tronco os parâmetros de maior correlação foram os danos de batidas e lesões de casca, cavidades e orifícios de insetos e, para a base da árvore tem-se maior correlação apenas para a área livre de canteiro.

\section{REFERÊNCIAS}

ALMEIDA, L. T.; MONTEIRO, L. I. B.; SILVA, F. B.; de PAULA CORRÊDO, L.; CESTONETTO, L. B. Locação de corredores ecológicos e área de preservação permanente na Universidade Federal de Viçosa. Nativa, Sinop, v. 4, n. 6, p. 412-418, 2016.

BEZERRA, M. B. S. Arborização da Avenida Jerônimo Rosado no município de Baraúna - RN, Brasil. Revista da Sociedade Brasileira de Arborização Urbana, Piracicaba, v. 12, n. 1, p. 122 $131,2017$.

BISPO, L. F. P. Aproveitamento de Resíduos da Arborização Urbana para a Fabricação de Brinquedos. 2017. 107f. Trabalho de conclusão de curso (Bacharelado em Engenharia Florestal) - Universidade de São Paulo, Piracicaba, 2017.

BOBROWSKI, R.; VASHCHENKO, Y.; BIONDI, D. Qualidade Visual da Paisagem do Parque Natural Municipal Tanguá, Curitiba-PR. Revista da Sociedade Brasileira de Arborização Urbana, Piracicaba, v. 05, n. 02, p. 19-39. 2010. 
BRIANEZI, D.; JACOVINE, L. A. G.; GONÇALVES, W.; ROCHA, S. J. S. S. Evaluation of afforestation on the main Campus of the Universidade Federal de Viçosa, Minas Gerais state, Brazil, Revista da Sociedade Brasileira de Arborização Urbana, Piracicaba, v. 8, n. 4, p. 85100, 2013.

CARMO, F. G. Repercussão do aumento da verticalidade sobre o conforto ambiental na cidade de viçosa-MG. 2007. 49f. Trabalho de conclusão de curso (Geografia) - Universidade Federal de Viçosa, Viçosa, 2007.

CARVAlHO, A. L. P.; FERREIRA, D; SANTOS, M. C. M. P. N. Análise de risco de queda de árvores: Tilia tomentosa Moench. Revista da Sociedade Brasileira de Arborização Urbana, Curitiba, v.14, n.3, p. 01-16, 2019.

COSTA E LIMA, R. M.; SILVA JÚNIOR, M. C. Inventário da arborização urbana implantada na década de 60 no plano piloto, Brasília, DF. Revista da Sociedade Brasileira de Arborização Urbana, Piracicaba, v. 5, n. 4, p. 110-127. 2010.

COSTA-LEONARDO, A. M. Cupins-Praga: Morfologia, Biologia e Controle. Rio Claro: Divisa, $2002.128 p$.

FINK, S. Hazard tree indentification by visual tree assessment (VTA): scientifically solid and practically approved. Arboricultural Journal, London, v. 32, n. 3, p. 139-155. 2009.

GONZÁLEZ, M. A. S. O que é análise estatística? São Leopoldo: Unisinos, 2000.

IMAÑA, E. J.; SILVA, G. F.; PINTO, J. R. R. Idade e crescimento das árvores. Brasília: Universidade de Brasília, Departamento de Engenharia Florestal, 2005. 43 p.

INTERNATIONAL SOCIETY OF ARBORICULTURE (ISA). Guia de Estudo para a Certificação do Arborista. Chamoaign:ISA, 2015. 377p.

MILANO, M. S.; DALCIN, E. C. Arborização de vias públicas. Rio de Janeiro: Light, 2000. 206 p.

PEREIRA, B. Análise dos efeitos do entorno urbano sobre o sistema radicular de árvores viárias de São Mateus do Sul-Paraná. 2017. 101f. Trabalho de Conclusão de Curso (Bacharelado em Engenharia Florestal) - Universidade Tecnológica Federal do Paraná, Dois Vizinhos, 2017.

PEREIRA, P. H.; TOPANOTTI, L. R.; DALLACORT, S.; MOTA, C. J.; BRUN, F. G. K.; SILVA, R. T. L. Estudo de caso do risco de queda de árvores urbanas em via pública na cidade de Dois Vizinhos-PR. Synergismus scyentifica, Pato Branco, v. 6, n. 1, p. 1-10, 2011.

PEREIRA, R. I. O sentido da paisagem e a paisagem consentida: projetos participativos na produção de espaço livre público. 2006. 203f. Tese (Doutorado em Arquitetura e Urbanismo) Faculdade de Arquitetura e Urbanismo, Universidade de São Paulo, 2006.

SAMPAIO, A. C. F.; DUARTE, F. G.; SILVA, E. G. C.; DE ANGELIS, B. L. D.; BLUN, C. T. Avaliação de árvores de risco na arborização de vias públicas de Nova Olímpia, Paraná, Revista da Sociedade Brasileira de Arborização Urbana, Piracicaba, v. 5, n. 2, p. 82-104, 2010.

SANTOS, C. Z. A.; FERREIRA, R. A.; SANTOS, L. R.; SANTOS, L. I.; GOMES, S. H.; GRAÇA, D. A. S. Análise qualitativa da arborização urbana de 25 vias públicas da cidade de Aracajú-SE.

Revista Ciência Florestal, Santa Maria, v. 25, n. 3, p. 751-763, 2015. 
SCHALLENBERGER, L. S.; ARAÚJO, A. J.; ARAÚJO, M. N.; DEINER, L. J.; MACHADO, G. O. Avaliação da condição de árvores urbanas nos principais parques e praças do município de IratiPR. Revista da Sociedade Brasileira de Arborização Urbana, Piracicaba, v. 5, n. 2, p. 105123, 2010.

SEITZ, R. A. A avaliação visual das árvores de risco. Revista Ação Ambiental, Viçosa, v. 8, n. 33, p. 15-20, 2005.

SHORTLE, W.C.; DUDZIK, K.R.; SMITH, K.T. Development of wood decay in wound-initiated discolored wood of eastern red cedar. Holzforschung-International Journal of the Biology, Chemistry, Physics and Technology of Wood, Berlin, v. 64, n. 4, p. 529-536, 2010.

SILVA, V. de F. Neutralização de carbono: adaptabilidade e desenvolvimento de espécies florestais no ambiente urbano. 2019. 57f. Dissertação (Mestrado em Ciência Florestal) Universidade Federal de Viçosa, Viçosa, 2019.

SPATZ, H.C.; NIKLAS, K. J. Modes of failure in tubular plant organs. American Journal of Botany, San Luis, v. 100, n. 2, p.01-07, 2013.

STENICO, J.; PACHECO, F. D.; VENIER, M.P.M; CERIMARCO, M.J.C; SILVA FILHO, D. F. da; LEÃO, M. M. Análise da gestão pública na arborização urbana em municípios do estado de São Paulo. Revista da Sociedade Brasileira de Arborização Urbana, Curitiba, v.14, n.3, p. 81-92, 2019. 